\title{
BIM Research Topics and Progress in the Construction Field: Analysis Based on Knowledge Mapping
}

\author{
Hongxiong Yang ${ }^{1}$, Duo Wang ${ }^{2 *}$ \\ ${ }^{1}$ School of Management, Tianjin University of Technology, Tianjin, China. \\ ${ }^{2}$ School of Management, Tianjin University of Technology, Tianjin, China.
}

\begin{abstract}
The CNKI database and the WOS database are used as data retrieval sources for research literature related to BIM technology at home and abroad. Based on scientometrics and bibliometrics, through the analysis of keywords co-occurrence analysis, the hotspots and frontiers of BIM technology research in the construction field are quantitatively analysed, revealing the evolutionary trend of BIM technology research in the construction field. The research finds that BIM technology research in the construction field at home and abroad has roughly gone through three stages. Based on the combing of research frontiers and research hotspots, and analysis of their evolution trends, future research on BIM technology in the field of architecture will focus on the following directions: BIM technology is combined with the Internet of Things and cloud computing to conduct research, focusing on the application of BIM technology in risk management and the application of VR virtual reality technology.
\end{abstract}

\section{Introduction}

The transformation and upgrading of the construction industry is inseparable from the support and in-depth application of information technology. However, how to accelerate the development of informationization and intelligentization of the construction industry and improve productivity has become a problem facing the construction industry. The emergence of BIM technology has brought opportunities to the transformation and upgrading of the construction industry.

In recent years, in the field of BIM application and development obstacles, the domestic academic community has adopted different methods and made many useful explorations and analyses from different perspectives. For example, He Qing hua ${ }^{[1]}$ and others considered from the perspective of the entire industry and pointed out that the existing construction industry system, standard differences and domestic standards are the obstacles that need to be broken for the promotion and application of BIM, inducing BIM in the construction stage and operation and maintenance. The main reason for the lack of phase application is the lack of BIM integrated management and integrated application models. Tang Qi and Luo Shi peng [2] conducted detailed research on the application of BIM technology in the bidding stage of construction engineering projects, highlighting the application advantages and application value of BIM technology compared with traditional models, finally, based on the staged cost management process, a cost management process based on BIM technology for the construction project bidding stage was constructed. Wu Qiang ${ }^{[3]}$ analyzed and introduced the technical advantages of BIM from the perspective of property management and equipment operation and maintenance. Its applications include: can improve the level of fire emergency treatment, emergency response to engineering, enhance security capabilities, reserve conditions for maintenance and replacement of equipment, statistics of building data, personnel positioning, and so on. As a new concept and technology, BIM has become the focus of attention of the construction industry and domestic and foreign scientific researchers. However, due to the short time it takes, the content, topics, and methods involved are very extensive, it is necessary to comprehensively understand the research hotspots and evolution trends of BIM technology in the field of construction in recent years. Based on this, this article is based on bibliometric theory, using a combination of qualitative and quantitative methods, and using CiteSpace software as a visual analysis tool to analyse the SCI, EI, CSSCI, CSCD, core journals and core collections of WOS in CNKI. The related research of BIM technology in the field is organized and analysed, and the evolution trend of BIM technology related research in the construction field, then analyse the future development direction of BIM technology.

\section{Atlas of scientific knowledge and CiteSpace}

With the development of information visualization, various tools for drawing knowledge maps have emerged. Among them, CiteSpace knowledge visualization

\footnotetext{
* Corresponding author: 183142326@stud.tjut.edu.cn
} 
software is unique and has become one of the most popular knowledge map drawing tools today. CiteSpace software system is information visualization software developed by Dr. Chaomei Chen, a Chinese scholar in the School of Information Science and Technology, Drexel University, which is mainly used to measure and analyze scientific literature data. It can be used to draw science and technology the knowledge map of domain development visually displays the information panorama of the scientific knowledge field, and identifies key documents, hot research and cutting-edge directions in a scientific field. CiteSpace software system was first developed in 2004. It has the advantages of being scientifically effective and easy to use. At the same time, its visual effects are rich and beautiful, so it is widely used in the field of information science at home and abroad. It is important to note that when downloading CiteSpace software, you must download JAVA, because CiteSpace software can only run normally in the JAVA language environment.

\section{Data sources and analysis}

The data in this article mainly comes from China Knowledge Network (CNKI) and Web of and WOS was used as the data source of foreign research literature information. In the search of research literature, "BIM" was used as the subject line search. Among the source categories, SCI, EI, CSSCI, CSCD, and core journals were selected. After manual search, 576 records were found. In the WOS retrieval process, the database was selected from the core WOS collection, and a search using "BIM" as the key word yielded a total of 6,767 results. However, considering the huge data, the "Construction Engineering", "Architectural field", and "BIM" is used as a subject and keyword to search. Since the start of foreign BIM applications is relatively earlier than in China, the time is set to the 20 years from 2000 to 2019. Select the citation index to search in more settings. A total of 385 articles were found.

The research time of this article in CNKI is set from 2006 to 2019. The selected 457 articles were exported and used for visual analysis. The 385 articles retrieved from the WOS core collection were screened, and the results obtained 368 articles. After sorting by time, it was found that within the selected range, the earliest one of the documents was also in 2006. Therefore, when using CiteSpace software for visual analysis, the time was set to 2006-2019. Similarly, the 368 documents selected in the WOS were exported for visual analysis.

The keywords of the paper are a high-level summary of the content of the article. The author usually chooses the technical terms of the article very carefully ${ }^{[4]}$, which makes the keywords a reliable indicator of the content of the article. Assuming that the authors carefully select keywords, they can analyze the hot content and topic distribution of specific subject areas through cooccurrence analysis of keywords, and explore the focus of the authors. The identified focus is a research hotspot in this field.
Using CiteSpace software set the relevant parameters as follows: select the data as CNKI, WOS, node selection keyword, time from 2006 to 2019 , time slice is set to 1 year, threshold is set to Top50, others are the default parameter. Get the keyword co-occurrence network map and further refine it. CiteSpace interface settings select Minimum Spanning Tree, sort out the top ten keywords to get Table 1,2.

Table 1 Top ten keywords in CNKI

\begin{tabular}{c|c|c|c|c}
\hline $\begin{array}{c}\text { Serial } \\
\text { number }\end{array}$ & Keywords & $\begin{array}{c}\text { Frequency } \\
\text { of } \\
\text { occurrence }\end{array}$ & Centrality & $\begin{array}{c}\text { Earliest } \\
\text { year }\end{array}$ \\
\hline 1 & BIM & 194 & 0.63 & 2012 \\
\hline 2 & BIM & 120 & 0.29 & 2008 \\
\hline 3 & $\begin{array}{c}\text { BIM } \\
\text { technology }\end{array}$ & 52 & 0.5 & 2012 \\
\hline 4 & Informatization & 31 & 0.16 & 2012 \\
\hline 5 & BIM & 23 & 0.18 & 2012 \\
\hline 6 & application & 18 & 0.11 & 2013 \\
\hline 7 & $\begin{array}{c}\text { Prefabricated } \\
\text { building }\end{array}$ & 17 & 0.16 & 2017 \\
\hline 8 & $\begin{array}{c}\text { Project } \\
\text { management }\end{array}$ & 12 & 0.06 & 2014 \\
\hline 9 & $\begin{array}{c}\text { High-rise } \\
\text { building }\end{array}$ & 12 & 0.08 & 2017 \\
\hline 10 & $\begin{array}{c}\text { Deepening the } \\
\text { design }\end{array}$ & 11 & 0.11 & 2017 \\
\hline
\end{tabular}

It can be seen from Table 1 that the earliest keyword in the research of BIM technology in the field of construction in China is "building information model", which appeared in 2008. This article mainly compares the quantity calculation software of other platforms Advantages and disadvantages, a new BIM-based architectural software development platform model is proposed. The most frequently appearing keyword is "BIM", which appears 194 times, followed by "Building Information Model", "BIM Technology", "Informatization", etc. The keyword "application" seems to be too general. Check the related articles and find that it mainly refers to the application in engineering management, project construction, green building, engineering cost, etc. The key words of "fabricated building", "high-rise building" and "deepening design" have been the research hotspots in the past two years. In addition, "3D visualization", "cost control", "cloud computing", "big data", "virtual simulation" and so on is also hot research topics in recent years.

Table 2 Top 10 keywords in WOS

\begin{tabular}{c|c|c|c|c}
\hline $\begin{array}{c}\text { Serial } \\
\text { number }\end{array}$ & Keywords & $\begin{array}{c}\text { Frequency } \\
\text { of } \\
\text { occurrence }\end{array}$ & Centrality & $\begin{array}{c}\text { Earlie } \\
\text { st year }\end{array}$ \\
\hline 1 & BIM & 126 & 0.08 & 2010 \\
\hline 2 & $\begin{array}{c}\text { constructio } \\
\mathrm{n}\end{array}$ & 88 & 0.12 & 2010 \\
\hline 3 & design & 68 & 0.06 & 2013 \\
\hline 4 & $\begin{array}{c}\text { building } \\
\text { informatio } \\
\mathrm{n} \\
\text { modeling }\end{array}$ & 65 & 0.03 & 2010 \\
\hline 5 & system & 56 & 0.06 & 2011 \\
\hline 6 & $\begin{array}{c}\text { manageme } \\
\text { nt }\end{array}$ & 54 & 0.08 & 2011 \\
\hline
\end{tabular}




\begin{tabular}{c|c|c|c|c}
\hline 7 & BIM & 48 & 0.12 & 2013 \\
\hline 8 & model & 48 & 0.05 & 2011 \\
\hline 9 & framework & 43 & 0.08 & 2015 \\
\hline 10 & technology & 34 & 0.08 & 2011 \\
\hline
\end{tabular}

It can be seen from Table 2 that the keyword most researched on BIM technology in the foreign construction field is also "BIM", which appeared 126 times, followed by "construction" and "design", respectively, appears 88 times and 68 times. Among the top ten keywords, the closest to now is the "framework" that was started in 2015, which is understood as the "framework of buildings". Articles containing this keyword explore the improvement of BIM technology in lean and green, Virtual facilities and other applications. The research hotspots in the past two years in foreign countries mainly focus on "model view definition (mvd)" (model view definition MVD), "accuracy" (precision), "prefabrication" (prefabricated building components) and so on. On the whole, the frequency of occurrence of high-frequency words in BIM technology in foreign construction fields is relatively even, and research hotspots are scattered. It is not limited to a single research direction, and there are many cross-researches between fields. In summary, through knowledge maps, it can be found that "3D visualization", "cloud computing", "big data", "virtual simulation", etc. have been the hotspots of BIM technology research in the construction field at home and abroad in recent years.

On the CiteSpace setting interface, analyze the data in CNKI and WOS, select the time period from 2006 to 2019 set in this article, set the time interval to 5 years, and select the threshold to Top50, with the middle and high of each time zone the top 50 cited articles are selection data. In order to eliminate some redundant information, the most essential relationships can be smoothly extracted from a given set of similar data. While selecting the "clustering perspective" function in Visualization, only the most closely related methods are retained to simplify the network, to obtain a clearer citation network clustering map. Select the Pathfinder algorithm in the "Pruning" function and use Burstness function in the CiteSpace software to adjust $\alpha 1 / \alpha 0$ to a suitable size. After testing, adjust it to 5 the data obtained are most complete. The results are shown in Figures 1, 2 below. Where "LM", "II", "LC" respectively represent "Integrated management", "Information integration", "Lean construction".

\section{Top 9 Kefyroords with the Strongess Citation Bursts}

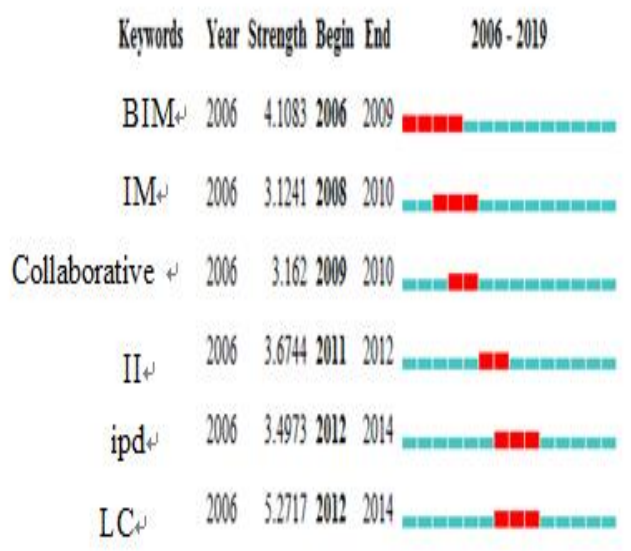

Figure 1 Emergent Chinese words with the most citations

It can be seen that the "building information model" has a mutation intensity of 4.1083 from 2006 to 2009 , indicating that during this period BIM was attracted by more scholars, that is, it was in the preliminary research and promotion stage of BIM. Around 2010, scholars researched The keywords became "integrated management" and "collaborative work"; then came "information integration"; from 2012 to 2014, scholars' main research became BIM technology and "ipd (integrated product development)" And "lean construction", the "lean construction" that appeared during the same period was even more prominent, and its mutation intensity reached 5.2717, indicating that during this period domestic BIM technology research was further strengthened and became the flashpoint of domestic research. -Informatization appeared in 2016. Nowadays, information, computer and network technologies are developing rapidly. How to better apply BIM technology in the context of informatization has become the main research direction. There are no emergent words in the past two years in foreign studies. The closest emergent word is the "building information model" from 2013 to 2016. The highest emergence intensity is from "building information modeling" from 2010 to 2014 . 5.6423, indicating that it has the highest research interest at this stage. Followed by "construction", its emergence intensity is 5.429.

Based on the above studies, it is found that the research hotspots of BIM technology in China's construction field are mainly divided into three stages. The first stage is from 2006 to 2010, and the main keyword during this period is "building information model". The second stage is from 2011 to 2015. The main keywords of the research literature during this period have evolved into "BIM technology" and "BIM standards" "," Informatization "," high-rise building "," design "," optimization "and other words; the third stage is from 2016 to the present, the key words are" research "," Internet of things ". Similarly, the development of foreign BIM can be divided into three stages. The first stage is from 2006 to 2012 . The main research topics are 
"building information model", "CAD", "point cloud data", "construction safety", and "engineering", "education, "' benchmarking, "and more. The second stage is from 2013 to 2015, and the keywords have changed to "innovation", "decision making", "operations", "framework", "lean construction", "and integration" and so on. The third stage is from 2016 to the present. The keywords are "virtual reality technology", "classification", "life cycle", "facility management", and "risk management". Words such as "reconstruction", "design", and "BIM" are used throughout the research of BIM technology, and there are related literatures to this day. It can be seen that the research and development of BIM technology in foreign construction fields is mainly based on risk management and virtual reality technology.

\section{Top 5 Keywords with the Strongest Citation Bursts}

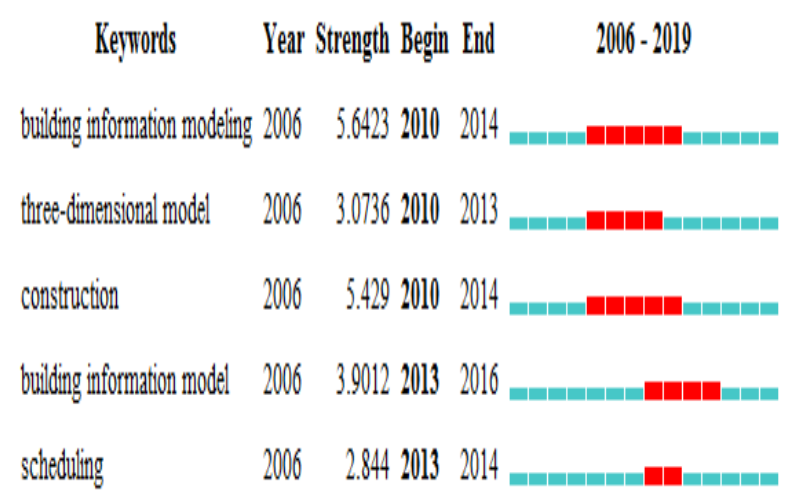

Figure 2 Emergent English words with the most citations

\section{Conclusion}

According to the above research and analysis, it can be known that "Internet of Things", "cloud computing", "VR virtual reality technology", and "risk management" will continue to become research hotspots in BIM technology in the construction field. Based on this, In the future, the development direction of BIM technology research in the construction field will be the integration of BIM and other technologies to form "BIM +", such as "BIM + Internet of Things", "BIM + Cloud Computing", and "BIM + VR". In addition, the application of BIM technology in risk management will be gradually valued.

\section{Reference}

1. He Qinghua, Qian Lili, Duan Yunfeng, Li Yongkui. Research on Status and Obstacles of BIM Application at Home and Abroad [J] .Journal of Engineering Management, 2012,26 (01): 12-16.

2. Tang Qi, Luo Shipeng. Research on BIM Cost Management of Construction Project Based on BIM [J] .Building Materials World, 2018, 39 (01): 70-73.
3. Wu Qiang. Application of BIM model in property management and equipment operation and maintenance $[\mathrm{J}]$.China Property Management, 2015 (05): 42-43.

4. Whittaker J. Creativity and Conformity in Science: Titles, Keywords and Co-word Analysis [J].Social Studies of Science an International Review of Research in the Social Dimensions of Science \&Technology. 1989, 19(3):473-496. 